\title{
Potencial antimicrobiano de óleos vegetais ozonizados frente a espécies bacterianas: uma revisão integrativa
}

\author{
Antimicrobial potential of ozonized vegetable oils against bacterial species: an integrative review \\ El potencial antimicrobiano de los aceites vegetales ozonizados contra las especies bacterianas: una \\ revisión integrativa
}

Recebido: 28/01/2021 | Revisado: 02/02/2021 | Aceito: 09/02/2021 | Publicado: 13/02/2021

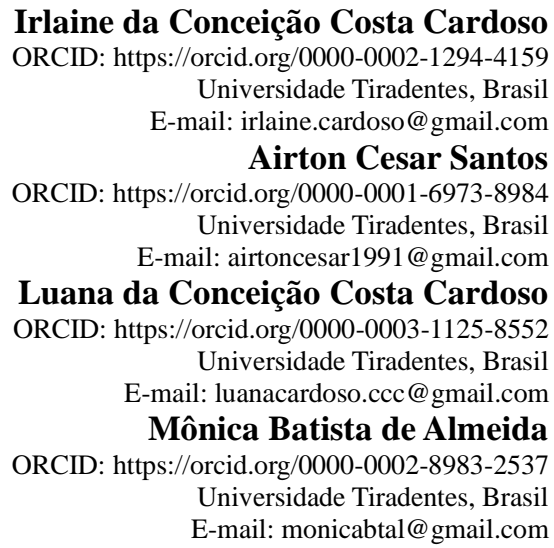

\begin{abstract}
Resumo
A crescente incidência de infecções bacterianas em lesões crônicas de pele é um problema mundial. Pesquisas sobre métodos terapêuticos alternativos, como utilização de óleos vegetais ozonizados, tornaram-se promissoras. Dessa forma, objetivou-se evidenciar a ação antimicrobiana de óleos vegetais ozonizados frente a estirpes bacterianas. Tratase de uma revisão integrativa realizada através de buscas nas seguintes bases de dados e bibliotecas: Literatura LatinoAmericana e do Caribe em Ciências da Saúde, Sistema Online de Busca e Análise de Literatura, Biblioteca Nacional de Medicina dos Estados Unidos, Biblioteca Eletrônica Científica Online e dois bancos de dados da Elsevier (Science Direct e Scopus). Foram selecionados 11 artigos, 73\% desses trabalhos foram publicados nos últimos 5 anos, enquanto apenas 27\% foram publicados nos anos de 2011 e 2013. Houveram publicações da China, Itália, Brasil, Cuba, França e Turquia. Todos os trabalhos utilizaram métodos laboratoriais para avaliar o potencial antimicrobiano do óleo vegetal ozonizado. O efeito antibacteriano dos óleos relacionou-se às condições de ozonização que foram submetidos e sua composição final de peróxidos e ácidos carboxílicos. Verificou-se que esses compostos promoveram alterações celulares e impediram crescimento bacteriano, podendo induzir morte bacteriana. Através dessa revisão foi possível apresentar informações atualizadas sobre uma alternativa terapêutica promissora contra infecções bacterianas na pele.
\end{abstract}

Palavras-chave: Ozônio; Óleo vegetal; Bactérias; Antibacterianos.

\begin{abstract}
The increasing incidence of bacterial infections in chronic skin lesions is a worldwide problem. Research on alternative therapeutic methods, such as the use of ozonated vegetable oils, has become promising. Thus, it was aimed to evidence the antimicrobial action of ozonized vegetable oils against bacterial strains. This is an integrative review conducted through searches the following databases and libraries: Latin American and Caribbean Health Sciences Literature, Medical Literature Analysis and Retrieval System Online, National Library of Medicine, Scientific Electronic Library Online and two Elsevier databases (Science Direct e Scopus). 11 articles were selected, 73\% of these works were published in the last five years, while only 27\% were published in 2011 and 2013. There have been publications from China, Italy, Brazil, Cuba, France and Turquey. All studies used laboratory methods to assess the antimicrobial potential of ozonized vegetable oil. The antibacterial effect of the oils was related to the ozonation conditions that were submitted and their final composition of peroxides and carboxylic acids. It was found that these compounds promoted cellular changes and prevented bacterial growth, which could cause bacterial death. Through this review it was possible to present updated information on a promising therapeutic alternative against bacterial skin infections.
\end{abstract}

Keywords: Ozone; Plant Oils; Bacteria; Anti-Bacterial Agents. 


\begin{abstract}
Resumen
La creciente incidencia de las infecciones bacterianas en las lesiones cutáneas crónicas es un problema mundial. La investigación de métodos terapéuticos alternativos, como el uso de aceites vegetales ozonizados, se ha revelado promisoria. Así, se pretendía evidenciar la acción antimicrobiana de los aceites vegetales ozonizados frente a las cepas bacterianas. Se trata de una revisión integrativa realizada a través de búsquedas en las siguientes bases de datos y bibliotecas: Latin American and Caribbean Health Sciences Literature, Online System of Search and Analysis of Literature, National Library of Medicine of the United States, Online Scientific Electronic Library y dos bases de datos de Elsevier (Science Direct y Scopus). Se seleccionaron once artículos, 73\% de estos trabajos se publicaron en los últimos cinco años, mientras que solo el 27\% se publicaron en 2011 y 2013. Ha sabido publicaciones de China, Italia, Brasil, Cuba, Francia y Turquia. Todos los cuales utilizaron métodos de laboratorio para evaluar el potencial antimicrobiano del aceite vegetal ozonizado. El efecto antibacteriano de los aceites se relacionó con las condiciones de ozonización a las que fueron sometidos y su composición final de peróxidos y ácidos carboxílicos. Se constató que estos compuestos promovían alteraciones celulares e impedían el crecimiento bacteriano, lo que podía inducir la muerte de las bacterias. A través de esta revisión fue posible presentar información actualizada sobre una prometedora alternativa terapéutica contra las infecciones bacterianas de la piel.
\end{abstract}

Palabras clave: Ozono; Aceites vegetales; Bacterias; Antibacterianos.

\title{
1. Introdução
}

As lesões cutâneas crônicas representam um problema mundial no que se refere à saúde pública. São responsáveis por perda na qualidade de vida dos indivíduos, pois, a dificuldade de recuperação afeta diretamente aspectos psicológicos, sociais e econômicos (Silva et al., 2015; Bandeira et al., 2018; Macêdo et al., 2016).

A cronicidade dessas lesões geralmente está ligada a fatores que interferem na chamada cicatrização por primeira intenção. Assim, a infecção bacteriana corresponde ao fator de complicação mais frequente nessas lesões. Essas infecções estão propensas a apresentar uma etiologia polimicrobiana, seja por bactérias Gram positivas e/ou negativas (Chavaglia, Ohl, Contim, \& Gamba, 2015; Silva et al., 2018; Bonet, Lozano, \& Gatius, 2015).

As pesquisas apontam que entre as bactérias comumente isoladas nessas infecções, a Staphylococcus aureus lidera o número de casos, seguida pela Enterococcus faecium, Pseudomonas aeruginosa e Escherichia coli. Dessa forma, o tratamento mais adotado para essas infecções é a utilização de antimicrobianos (Heitkamp et al., 2018; Chaney et al., 2017).

Contudo, a exposição inadequada das bactérias aos antimicrobianos levou ao desenvolvimento de mecanismos de resistências aos antibióticos e com isso as falhas terapêuticas estão mais frequentes. Com a disseminação da resistência bacteriana através das práticas indevidas de higiene e uso indiscriminado desses antibióticos, o tratamento de pessoas com essa comorbidade está cada vez mais dificultado (Oli et al., 2017; Li et al., 2018; Cheng et al., 2018).

Métodos promissores de intervenção em infecções bacterianas ganharam relevância e novas pesquisas mostraram a eficácia dessas maneiras alternativas à antibioticoterapia. Diante disso, o interesse em estudos sobre a terapia com o ozônio (O3) ressurgiu e já demonstraram benefícios substanciais no que diz respeito à ação antimicrobiana e cicatricial nas lesões cutâneas crônicas (Dellalibera-Joviliano, Melo, \& Ceni, 2020; Giuliani, Ricevutti, Galoforo, \& Franzini, 2018; Smith, Wilson, Gandhi, Vatsia, \& Khan, 2017).

O O3 é uma molécula inorgânica formada por três átomos de oxigênio, caracterizado pelo seu poder oxidativo. Quando exposta a fluidos orgânicos ocorre a formação de moléculas reativas de oxigênio (O2) capazes de influenciar no metabolismo celular e na regeneração tecidual. Além disso, o contato com bactérias gera reações que promovem a destruição das células bacterianas. Atualmente, existem algumas formas de aplicação tópica do O3, como a utilização do óleo vegetal ozonizado (Ugazio, Tullio, Binello, Tagliapietra, \& Dosio, 2020; Smith et al., 2017; Néri et al., 2017).

Os óleos vegetais são ricos em lipídios insaturados que possuem ligações duplas carbono-carbono, por isso, a sua exposição ao O3 permite que a molécula fique reservada em uma forma mais estável, os ozonídeos. Além disso, o processo de ozonização do óleo também favorece a formação de peróxidos, hidroperóxidos e aldeídos. Os compostos gerados reagem com a membrana e o citoplasma das bactérias causando aumento da permeabilidade celular e alterações citoplasmáticas (Beltran, 
Jiménez, Amézquita-López, Martínez-Rodrigues, \& Chaidez, 2016; Lozano-Ledea et al., 2019; Zeng, \& Lu, 2018).

Dessa forma, o crescimento bacteriano é interrompido e o efeito bactericida é induzido. Por outro lado, a eficácia desse tratamento contra bactérias multirresistentes é explicada por que esses microrganismos não possuem ferramentas para impedir a ação oxidativa do O3. Ainda, em contato com a lesão, esses compostos também produzem reações capazes de ativar o sistema imunológico e produção de substâncias que aumentam a vascularização (Varol, Birdane, \& Keles, 2018; Oliveira et al., 2017; Logan, 2018).

Partindo dessa premissa, os efeitos antibacterianos da terapia com O3 mostraram-se promissores, uma vez que a resistência bacteriana aos antibióticos impede a eficácia dos tratamentos convencionais e consequentemente a recuperação das lesões crônicas de pele. Nesse contexto, o objetivo do presente trabalho foi realizar uma revisão integrativa da literatura a fim de avaliar o potencial antibacteriano presente em óleos vegetais ozonizados e fornecer informações completas sobre essa propriedade medicinal.

\section{Metodologia}

Foi realizada uma pesquisa através de revisão integrativa da literatura. Segundo Souza, Silva e Carvalho (2010), o objetivo desse tipo de revisão é fornecer informações condizentes ao tópico pesquisado com base em conhecimento científico. É um método altamente criterioso e extenso que permite inclusão de pesquisas e análises de dados resultando na redução de erros e vieses de buscas. O desenvolvimento do presente estudo foi feito de maneira qualitativa e descritiva, levando em consideração a habilidade interpretativa dos pesquisadores em relação a temática estudada (Pereira, Shitsuka, Parreira \& Shitsuka, 2018).

Seguindo a metodologia de Whittemore e Knafl (2005), a presente pesquisa foi feita a partir de seis estágios fundamentais: (1) Identificação do problema e formulação da questão norteadora; (2) buscas literárias com base em critérios de inclusão e exclusão; (3) determinação de informações que foram extraídas das pesquisas selecionadas; (4) análise detalhada dos dados; (5) interpretação dos resultados; (6) apresentação dos resultados da revisão.

O norteamento da presente revisão desenvolveu-se a partir da seguinte questão: O óleo vegetal ozonizado possui efeitos antimicrobianos frente a estirpes bacterianas? O levantamento das publicações ocorreu entre os meses de janeiro a abril de 2020. Para garantir o controle e identificação de descritores correspondentes, utilizou-se o Medical Subject Heading Terms (Mesh Terms). Assim, foram elaborados dois grupos de descritores combinados pelos operadores boleanos OR e AND: ozone AND oil AND bacteria AND microbiology e ozone AND oil AND bacteria OR microbiology.

As buscas na literatura ocorreram através dos recursos informacionais da Biblioteca Virtual de Saúde (BVS), indexados pelas bases de dados LILACS (Literatura Latino-Americana e do Caribe em Ciências da Saúde) e a MEDLINE (Sistema Online de Busca e Análise de Literatura), como também pela PUBMED (National Library of Medicine), SCIELO (Scientific Electronic Library Online) e dois bancos de dados da Elsevier: Science Direct e Scopus.

Os critérios para inclusão dos artigos foram: estudos publicados em periódicos internacionais e nacionais entre os anos de 2010 a 2020, a pesquisa incluiu artigos originais e ensaios clínicos disponíveis virtualmente em textos completos que abordaram o potencial antibacteriano do óleo vegetal ozonizado, publicados em inglês, português, espanhol e chinês. Já os critérios de exclusão foram: estudos cuja temática não tinha correlação estrita ao tema abordado nesta pesquisa, pesquisas duplicadas e trabalhos publicados em forma de resumos e pôsteres.

Dessa forma, o processo de avaliação e análise das referências foi feito por meio de três etapas. A primeira etapa consistiu na leitura dos títulos dos artigos, a segunda na leitura dos resumos e a terceira na análise das pesquisas na íntegra. Todas as etapas foram realizadas de maneira independente por pares a fim de excluir vieses de seleção. Todas as discordâncias foram avaliadas em conjunto para se obter um consenso. 
Posteriormente, a classificação dos artigos foi montada com base na identificação de autores, ano e país de publicação, base onde foram encontrados, resultados e conclusão. Na etapa interpretativa dos resultados foi realizada discussão entre os pesquisadores para identificar lacunas e recomendações acerca dos artigos analisados. Para essa etapa fez-se necessário a construção de um quadro sinóptico com a descrição das pesquisas incluídas.

\section{Resultados}

Foram encontradas 1.257 publicações, 592 na Scopus, 333 na MEDLINE, 284 na Science Direct, 29 na PUBMED, 11 na SCIELO e 8 na LILACS. Na primeira etapa de avaliação das publicações correspondente a seleção de títulos, foram excluídos 1.194 estudos que não atendiam aos critérios de inclusão, permanecendo assim 63 trabalhos. Na segunda etapa, a leitura dos resumos indicou a exclusão de mais 50 pesquisas, pois não abordavam sobre o efeito antimicrobiano do óleo ozonizado, seguiram para análise na íntegra, 13 trabalhos. Após leitura completa dos artigos selecionados, optou-se por excluir duas pesquisas por se tratar de revisões bibliográficas.

Quadro 1 - Síntese dos estudos incluídos quanto aos autores, ano de publicação, país, título e base, 2020.

\begin{tabular}{|c|c|c|c|c|}
\hline $\begin{array}{l}\text { Número } \\
\text { do artigo }\end{array}$ & $\begin{array}{l}\text { Autores e ano de } \\
\text { publicação }\end{array}$ & País & Título & Base \\
\hline 1 & Song et al., 2018 & China & $\begin{array}{l}\text { The antibacterial effect of topical ozone on the treatment of } \\
\text { MRSA skin infection }\end{array}$ & PUBMED \\
\hline 2 & Lu et al., 2018 & China & $\begin{array}{l}\text { Effect of ozone on Staphylococcus aureus colonization in } \\
\text { patients with atopic dermatitis }\end{array}$ & PUBMED \\
\hline 3 & $\begin{array}{l}\text { Elshinawy, Al-Madboly, } \\
\text { Ghoneim, \& El-Deeb, } \\
2018\end{array}$ & Egito & $\begin{array}{l}\text { Synergistic Effect of Niely Introduced Root Canal } \\
\text { Medicaments; Ozonated Olive Oil and Chitosan } \\
\text { Nanoparticles, Against Persistent Endodontic Pathogens }\end{array}$ & PUBMED \\
\hline 4 & $\begin{array}{l}\text { Moureu, Violleau, } \\
\text { Haimoud-Lekhal, \& } \\
\quad \text { Calmon, } 2015\end{array}$ & França & $\begin{array}{l}\text { Ozonation of sunflower oils: Impact of experimental } \\
\text { conditions on the composition and the antibacterial activity } \\
\text { of ozonized oils }\end{array}$ & PUBMED \\
\hline 5 & Zanardi et al., 2013 & Itália & $\begin{array}{l}\text { What Is the Best Strategy for Enhancing the Effects of } \\
\text { Topically Applied Ozonated Oils in Cutaneous Infections? }\end{array}$ & PUBMED \\
\hline 6 & Palacios e Rubiano, 2016 & Cuba & $\begin{array}{c}\text { Valoración microbiológica de un aceite ozonizado } \\
\text { antibacterial y reparador mediante prueba de eficácia } \\
\text { antimicrobiana }\end{array}$ & SCOPUS \\
\hline 7 & Zeng et al., 2020 & China & $\begin{array}{l}\text { Topical ozone therapy restores microbiome diversity in } \\
\text { atopic dermatitis }\end{array}$ & $\begin{array}{l}\text { SCIENCE } \\
\text { DIRECT }\end{array}$ \\
\hline 8 & Xiang et al, 2018 & China & $\begin{array}{l}\text { Bactericidal effect of ozonated camellia oil on } \\
\text { Staphylococcus aureus in vitro }\end{array}$ & MEDLINE \\
\hline 9 & $\begin{array}{l}\text { Pietrocola, Ceci, Preda, } \\
\text { Poggio, \& Colombo, } 2018\end{array}$ & Itália & $\begin{array}{l}\text { Evaluation of the antibacterial activity of a new ozonized } \\
\text { olive oil against oral and periodontal pathogens }\end{array}$ & MEDLINE \\
\hline 10 & $\begin{array}{l}\text { Özyıldız, Karagönlu, } \\
\text { Basal, Uzel, \& Bayraktar, } \\
2013\end{array}$ & Turquia & $\begin{array}{l}\text { Micro-encapsulation of ozonated red pepper seed oil with } \\
\text { antimicrobial activity and application to nonwoven fabric }\end{array}$ & MEDLINE \\
\hline 11 & Guinesi et al. 2011 & Brasil & Ozonized Oils: A Qualitative and Quantitative Analysis & SCIELO \\
\hline
\end{tabular}

Fonte: Elaborado pelos autores (2020).

A seleção final correspondeu ao quantitativo de 11 artigos que atenderam aos critérios de inclusão e exclusão. O maior quantitativo de pesquisas foi publicado nos últimos cinco anos (73\%), enquanto $27 \%$ são dos anos de 2011 e 2013 . A maior produção foi da China com quatro artigos (37\%), seguida da Itália com dois (18\%), as outras publicações tiveram origem no Brasil, Cuba, Egito, França e Turquia (45\%). Foram realizadas descrições dos artigos incluídos neste trabalho, 
contendo o número do artigo, a autoria, o ano e país de publicação, a base de dados onde foi encontrado e o título (Quadro 1).

Quadro 2 - Síntese dos estudos incluídos quanto aos resultados e conclusões, 2020.

\begin{tabular}{|c|c|c|}
\hline $\begin{array}{l}\text { Número } \\
\text { do artigo }\end{array}$ & Resultados & Conclusões \\
\hline 1 & $\begin{array}{l}\text { O óleo de camélia ozonizado eliminou aproximadamente } 100 \% \\
\text { das duas estirpes de } S \text {. aureus testadas, sendo uma delas } \\
\text { resistente a meticilina. Dois pacientes com tratamento tópico } \\
\text { das lesões não apresentaram microrganismos na cultura } \\
\text { realizada dias após a aplicação de água e óleo ozonizado. }\end{array}$ & $\begin{array}{c}\text { O óleo ozonizado demonstrou um grande potencial } \\
\text { antibacteriano quando testado in vitro. No tratamento de } \\
\text { lesões infectadas também mostrou eficácia na eliminação } \\
\text { das bactérias Gram positivas, entre elas microrganismos } \\
\text { resistentes. }\end{array}$ \\
\hline 2 & $\begin{array}{l}\text { Lesões de dermatite atópica infectadas por Staphylococcus } \\
\text { aureus, tratadas com água e óleo de camélia ozonizado } \\
\text { melhoraram significativamente. As análises microbiológicas da } \\
\text { lesão mostraram redução da carga bacteriana já nos primeiros } 3 \\
\text { dias de tratamento. }\end{array}$ & $\begin{array}{l}\text { A ozonioterapia tópica com a utilização da água } \\
\text { ozonizada e do óleo de camélia ozonizado pode reduzir } \\
\text { significativamente a colonização de Staphylococcus } \\
\text { aureus em pacientes com dermatite atópica. }\end{array}$ \\
\hline 3 & $\begin{array}{l}\text { O teste de micro diluição em caldo revelou que os compostos } \\
\text { tinham altas concentrações inibitórias e bactericidas. O óleo de } \\
\text { oliva ozonizado correspondeu ao segundo agente } \\
\text { antimicrobiano capaz de reduzir biofilmes bacterianos e } \\
\text { promover a diminuição da adesão celular de microrganismos } \\
\text { aos fibroblastos. }\end{array}$ & $\begin{array}{l}\text { Em relação ao óleo ozonizado, sua capacidade } \\
\text { antimicrobiana é atribuída à estabilização do ozônio } \\
\text { como ozonídio, além de outros produtos, incluindo } \\
\text { peróxido, hidro peróxido, diperóxido, poli peróxido e } \\
\text { aldeídos. O óleo ozonizado teve os menores efeitos } \\
\text { citotóxicos. }\end{array}$ \\
\hline 4 & $\begin{array}{l}\text { O óleo de girassol clássico tinha mais insaturações. A ozonólise } \\
\text { na presença de água gerou maior índice de peróxidos; a acidez } \\
\text { foi mais alta com tempo de ozonização maior e os óleos } \\
\text { apresentaram ação antibacteriana contra as estirpes testadas. Na } \\
\text { ausência de água os valores de peróxido e acidez foram } \\
\text { menores e os óleos não desempenharam efeitos antibacterianos }\end{array}$ & $\begin{array}{l}\text { É necessário um tempo maior de ozonização para } \\
\text { consumo das insaturações do óleo. Os peróxidos e acidez } \\
\text { aumentam graças a reação de ozonização na presença de } \\
\text { água que favorece a formação de compostos oxigenados. } \\
\text { A ação antibacteriana foi mais demonstrada na presença } \\
\text { de maior concentração de peróxidos e acidez. }\end{array}$ \\
\hline 5 & $\begin{array}{l}\text { Nenhuma bactéria viável foi encontrada após seis horas de } \\
\text { tratamento com óleos de teor máximo de peróxido. A presença } \\
\text { de soro humano aumentou a sobrevivência de microrganismos } \\
\text { mesmo em concentrações mais altas do óleo e maior teor de } \\
\text { peróxido. }\end{array}$ & $\begin{array}{c}\text { A atividade antibacteriana depende de compostos } \\
\text { presentes no óleo ozonizado. A sobrevivência das } \\
\text { bactérias na presença do soro é explicada por que no } \\
\text { fluido existe antioxidantes que formam barreiras contra o } \\
\text { efeito antibacteriano. }\end{array}$ \\
\hline 6 & $\begin{array}{c}\text { Após exposição dos microrganismos ao óleo vegetal ozonizado, } \\
\text { foi encontrada uma redução de } 99,10 \% \text {. Mantiveram-se as } \\
\text { observações até o } 28^{\circ} \text { dia e os resultados continuaram sendo } \\
\text { inibitórios. }\end{array}$ & $\begin{array}{l}\text { O estudo comprovou a eficácia do óleo ozonizado na } \\
\text { eliminação de diferentes representantes de } \\
\text { microrganismos Gram positivos e Gram negativos. }\end{array}$ \\
\hline 7 & $\begin{array}{c}\text { Após a terapia com a água e o óleo ozonizado houve redução do } \\
\text { processo inflamatório nas lesões de pele e eliminação dos } \\
\text { patógenos. Houve restauração da microbiota em lesões de } \\
\text { dermatite atópica. }\end{array}$ & $\begin{array}{c}\text { Os locais suscetíveis de dermatite atópica grave } \\
\text { apresentaram colonização por S. aureus e pouca } \\
\text { restauração da pele. Após tratamento com água } \\
\text { ozonizada e óleo de camélia ozonizado houve melhora } \\
\text { significativa. }\end{array}$ \\
\hline 8 & $\begin{array}{l}\text { O número de colônias nas placas tratadas com óleo de camélia } \\
\text { ozonizado foi consideravelmente menor que na placa tratada } \\
\text { com óleo comum. E os resultados da turbidimetria } \\
\text { demonstraram que a concentração de bactérias foi menor que } \\
\text { nos grupos que não foram tratados com o óleo ozonizado. }\end{array}$ & $\begin{array}{l}\text { O óleo de camélia ozonizada pode matar } \\
\text { significativamente o Staphylococcus aureus. Além disso, } \\
\text { o grau de ozonização para a produção de peróxidos e a } \\
\text { composição de determinado óleo ozonizado é essencial } \\
\text { para potencializar a ação antimicrobiana. }\end{array}$ \\
\hline 9 & $\begin{array}{l}\text { Todos os compostos testados apresentaram atividade } \\
\text { antibacteriana em espécies Gram negativas. Nenhuma inibição } \\
\text { do crescimento bacteriano na espécie Gram positiva usada foi } \\
\text { encontrada usando o óleo de oliva ozonizado. }\end{array}$ & $\begin{array}{l}\text { Foi demonstrada menor atividade antibacteriana do óleo } \\
\text { ozonizado, se comparados aos outros compostos. Trata-se } \\
\text { de um antisséptico relativamente moderado. }\end{array}$ \\
\hline
\end{tabular}




\begin{tabular}{|c|c|c|}
\hline 10 & $\begin{array}{l}\text { O óleo da semente de pimenta vermelha (RPSO) é composto } \\
\text { principalmente de ácido linoleico seguido de ácido oleico. Os } \\
\text { aldeídos são os principais produtos voláteis da reação após a } \\
\text { ozonização do óleo e ácidos carboxílicos também foram } \\
\text { detectados. O RPSO não teve efeito antibacteriano, já o óleo da } \\
\text { semente de pimenta vermelha ozonizado (ORPSO) e as } \\
\text { cápsulas do ORPSO desempenharam efeito antimicrobiano em } \\
\text { todas as estirpes testadas. }\end{array}$ & $\begin{array}{l}\text { O ORPSO possui atividade antimicrobiana considerável } \\
\text { contra microrganismos resistentes. O efeito } \\
\text { antimicrobiano do ORPSO pode ser explicado pela } \\
\text { presença de compostos antimicrobianos, como aldeídos e } \\
\text { ácidos carboxílicos (por exemplo, ácidos azelaico e } \\
\text { pelargônico) formados pelo processo de ozonização. }\end{array}$ \\
\hline 11 & $\begin{array}{l}\text { Diante das reações observadas nas análises colorimétricas, } \\
\text { notou-se ausência de ozônio e presença de formaldeído nos } \\
\text { óleos ozonizados. Os efeitos antimicrobianos podem ser } \\
\text { atribuídos aos compostos originados após a ozonólise e não as } \\
\text { moléculas de ozônio. }\end{array}$ & $\begin{array}{l}\text { Deve ser levada em consideração a concentração do } \\
\text { ozônio na reação, o tempo de aplicação e a penetração do } \\
\text { composto. O formaldeído é uma substancia tóxica e suas } \\
\text { concentrações devem ser avaliadas nesses óleos. }\end{array}$ \\
\hline
\end{tabular}

Fonte: Elaborado pelos autores (2020).

Em todos os estudos incluídos, foram realizadas pesquisas laboratoriais para evidenciar o efeito antibacteriano, sendo que três realizaram ainda a ozonioterapia tópica em pacientes com lesões de pele. Nas pesquisas laboratoriais, 10 estudos utilizaram métodos microbiológicos para avaliar o efeito antibacteriano, desses, dois fizeram ainda análise comparativa do óleo ozonizado com outras substâncias e dois realizaram caracterização química do óleo. Apenas um artigo não realizou testes microbiológicos, mas explicou o efeito antibacteriano com base nos resultados de testes químicos (Quadro 2).

\section{Discussão}

Após análises sucessivas das pesquisas incluídas e frente à correlação entre as evidências científicas encontradas, foram criados agrupamentos entre os resultados dos artigos e elaboradas algumas categorias sobre o óleo vegetal ozonizado. Essas categorias foram: 1. caracterização de óleos vegetais e o processo de ozonização; 2. análise e comparação do efeito antibacteriano dos óleos vegetais ozonizados; e 3. benefícios da ozonioterapia tópica em pacientes com lesões infectadas na pele.

Categoria 1. Caracterização de óleos vegetais e o processo de ozonização

Os óleos vegetais são substâncias que possuem moléculas ricas em insaturações (ligações duplas entre carbonos). Alguns autores afirmam que os veículos oleosos possuem grande capacidade reservatória e que essa característica acarretaria em vantagem terapêutica, pois, o princípio ativo desses óleos seria estabilizado por mais tempo (Guinesi et al., 2011; Almeida et al., 2016; Palacios, \& Rubiano, 2016).

Quando esses óleos são expostos à ozonização, a formação de novos compostos é favorecida devido à quebra das ligações duplas. O O3 reage com essas ligações e originam os ozonídeos. Além disso, está reação chamada de ozonólise gera compostos como os aldeídos, peróxidos e ácidos carboxílicos que são as principais moléculas responsáveis pela ação antimicrobiana desses óleos (Moureu, Violleau, Haimoud-Lekhal, \& Calmon, 2016; Kogawa et al., 2015; Ugazio et al., 2020).

Em estudo, Özyıldız, Karagönlu, Basal, Uzel e Bayraktar (2013), constataram que o óleo da semente de pimenta vermelha se caracteriza por grande presença de insaturações, sendo semelhante aos óleos de girassol e açafrão. Eles ainda evidenciaram que após ozonizado, o óleo de pimenta seria grande reservatório de aldeídos e ácidos carboxílicos. Já Moureu, Violleau, Haimoud-Lekhal e Calmon (2015), demonstraram que óleos de girassóis ozonizados por tempo mais prolongado e na presença de água possuíam maiores índices de acidez e peróxidos. 
Categoria 2. Análise e comparação do efeito antibacteriano dos óleos vegetais ozonizados

As moléculas geradas após a ozonização possuem propriedades oxidativas que confere mecanismos antibacterianos ao óleo ozonizado. Os compostos do óleo, quando em contato com bactérias, interagem com a parede celular e membrana plasmática, isso gera alterações na permeabilidade da célula e consequentemente danos citoplasmáticos irreversíveis que impedem a síntese proteica. Assim, o crescimento celular é inibido, podendo acarretar na morte bacteriana (Özy1ldız et al., 2013; Pietrocola, Ceci, Preda, Poggio, \& Colombo, 2018; Elshinawy, Al-Madboly, Ghoneim, \& El-Deeb, 2018; Xiang et al., 2018).

Na pesquisa de Moureu et al. (2015), foi evidenciado o efeito antibacteriano do óleo de girassol ozonizado contra estirpes de $S$. aureus, E. coli e $S$. uberis. Verificou-se que as concentrações inibitórias mínimas para as três espécies variaram de 1,25 a $40 \mathrm{mg} / \mathrm{ml}$. A ação antibacteriana também foi relatada por Zanardi et al. (2013), entre os microrganismos testados estavam a $S$. aureus, P. aeruginosa e E. faecalis. Observou-se que nesses testes, após 6 horas de exposição das bactérias ao óleo de gergelim ozonizado, nenhuma bactéria viável foi encontrada.

Em um estudo comparativo, foram utilizados o óleo de oliva ozonizado e nanopartículas de prata e quitosana. O óleo foi o segundo melhor antimicrobiano capaz de inibir o crescimento bacteriano de espécies Gram positivas. Além disso, foi relatada a capacidade de inibir a formação de biofilmes e a aderência microbiana a fibroblastos. Evidenciou-se ainda que o óleo de oliva ozonizado foi o que menos apresentou efeitos citotóxicos nas células humanas (Elshinawy et al., 2018).

Por outro lado, no estudo comparativo de Pietrocola et al. (2018), o óleo de oliva ozonizado exerceu um efeito moderado contra bactérias, visto que, não foi eficaz contra microrganismos Gram positivos. Dessa forma, devem ser levadas em consideração a composição dos óleos vegetais e as condições de ozonização para produção de compostos antibacterianos que potencializam a ação desses óleos frente a várias espécies de bactérias (Guinesi et al., 2011; Xiang et al., 2018).

Categoria 3. Benefícios da terapia tópica com ozônio em pacientes com lesões infectadas na pele

As infecções em lesões de pele é uma problemática que gera perdas na qualidade de vida dos pacientes. Há vários microrganismos associados a essas infecções, mas o principal causador continua sendo o Staphylococcus aureus que além de ser um patógeno oportunista, desenvolveu resistências ao longo do tempo. A resistência a meticilina é a principal associada ao S. aureus (Bandeira et al., 2018; Lacey, Geoghegan, \& McLoughlin, 2016).

Mediante a incidência dessas infecções e as resistências que muitas vezes são derivadas da antibioticoterapia, surgiu a necessidade de investigar a eficácia de tratamentos alternativos. Assim, alguns pesquisadores avaliaram a utilização da terapia tópica com ozônio. Essa terapia consiste na aplicação de água ozonizada e óleo vegetal ozonizado nas lesões da pele durante determinado tempo (Oli et al., 2017; Anzolin, Silveira-Kaross, \& Bertol, 2020; Zeng et al., 2020).

Song et al. (2018) utilizaram água ozonizada e óleo de camélia ozonizado em dois pacientes com diagnóstico de lesões ulcerativas infectadas por S. aureus e Methicillin-resistant Staphylococcus aureus (MRSA). Ambos os pacientes foram submetidos a lavagens e desbridamento das lesões com água ozonizada e o óleo vegetal foi aplicado duas vezes ao dia durante algumas semanas. Após utilização da terapia houve melhora significativa das lesões nesses pacientes e não foi encontrada colonização bacteriana.

A limpeza inicial das secreções nessas lesões é de extrema importância para eficácia da terapia como óleo ozonizado. A presença desses exsudatos pareceu impedir os efeitos dos compostos ozonizados, uma vez que as biomoléculas encontradas possuem capacidade antioxidante que pode inibir a ação oxidativa do ozônio e viabilizar a colonização das bactérias (Song et al., 2018; Zanardi et al., 2013).

Outras pesquisas também demonstraram que a ozonioterapia pode restaurar o equilíbrio da microbiota em pacientes com dermatite atópica. Nesses pacientes, a taxa de S. aureus era alta e tinha correlação com a gravidade das lesões, após o 
tratamento foi relatado redução do patógeno e melhora nas lesões em pouco tempo de aplicação de água e óleo de camélia ozonizado (Zeng et al., 2020; Lu et al., 2018).

É reconhecido que existem limitações na presente revisão em virtude da escassez de estudos que demonstrem os efeitos do óleo vegetal ozonizado. Ainda, vale ressaltar que diferenças entre os métodos de armazenamento e exposições a temperaturas podem interferir na eficácia dos óleos e consequentemente nos resultados dos testes laboratoriais dos estudos.

\section{Considerações Finais}

O efeito antibacteriano de óleos vegetais ozonizados está correlacionado com as condições de ozonização aos quais foram submetidos. Óleos com maiores concentrações de insaturações e acidez são melhores para produção de peróxidos e ácidos carboxílicos. Ainda, a presença de água no processo de ozonização e tempo maior de reação do ozônio com o óleo contribuem positivamente para a melhora na ação contra bactérias.

Esta revisão possibilitou evidenciar indiretamente a capacidade antibacteriana que o óleo vegetal ozonizado possui contra estirpes Gram positivas e Gram negativas. Foi constatado ainda que espécies resistentes também são acometidas pelo efeito do óleo ozonizado e que lesões de pele tratadas com água e óleo ozonizados são propensas à redução da colonização bacteriana e aumento da regeneração tecidual.

Este trabalho torna-se relevante por apresentar informações atualizadas sobre possível alternativa terapêutica frente a infecções bacterianas de pele. Diante disso, é de grande importância a produção de mais pesquisas laboratoriais para avaliação da ação antibacteriana de óleos vegetais ozonizados. Sugere-se ainda a execução de estudos que reforcem as concentrações de ozônio empregadas nas formulações oleosas destinadas a terapêutica antimicrobiana. A expansão científica desses trabalhos pode subsidiar no reconhecimento e difusão da ozonioterapia em pesquisas e tratamentos clínicos.

\section{Referências}

Almeida, N. R., Beatriz, A., Arruda, E. J., Lima, D. P., Oliveira, L. C. S., \& Micheletti, A. C. (2016). Ozonized vegetable oils: Production, chemical characterization and therapeutic potential. Em B. Holt (Ed.), Vegetable Oil: Properties, Uses and Benefits (pp. 129-160). Nova Science Publishers.

Anzolin, A. P., Silveira-Kaross, N. L., \& Bertol, C. D. (2020). Ozonated oil in wound healing: what has already been proven? Medical Gas Research, 10 (1), 54.

Bandeira, L. A., Santos, M. C., Duarte, E. R. M., Bandeira, A. G., Riquinho, D. L., \& Vieira, L. B. (2018). Redes sociais de portadores de lesão cutânea crônica: o cuidado de enfermagem. Revista Brasileira de Enfermagem, 71 (1), 697-705.

Beltran, M. S. Jiménez, M., Amézquita-López, B. A., Martínez-Rodrigues, C., \& Chaidez. (2016). Antibacterial activity of ozonized olive (olea europaea 1.) And venadillo (swietenia humilis zucc.) Oils against Escherichia coli and Staphylococcus aureus. The Journal of Microbiology, Biotechnology and Food Sciences, 6 (3), 947.

Bonet, C. M., Lozano, S. A., \& Gatius, J. R. (2015). Prevalencia de infección por Staphylococcus aureus resistente a meticilina en heridas crónicas en atención primaria de Lleida: estúdio retrospectivo. Gerokomos, 26 (4), 157-161.

Chaney, S. B., Ganesh, K., Mathew-Steiner, S., Stromberg, P., Roy, S., Sen, C. K., \& Wozniak, D. J. (2017). Histopathological comparisons of Staphylococcus aureus and Pseudomonas aeruginosa experimental infected porcine burn wounds. Wound Repair and Regeneration, 25 (3), 541-549.

Chavaglia, S. R. R., Ohl, R. I. B., Contim, D., \& Gamba, M. A. (2015). Pessoas que convivem com feridas: uma reflexão teórica. Revista Família, Ciclos de Vida e Saúde no Contexto Social, 3 (2), 88-94.

Cheng, M., Zhang, L., Zhang, H., Li, X., Yanmei, W., Xia, F., Wang, B., Cai, R., Guo, Z., Zhang, Y., Ji, Y., Sun, C., Feng, X., Lei, L., Yang, Y., Han, W., \& $\mathrm{Gu}$, J. (2018). An ointment consisting of the phage lysin LysGH15 and apigenin for decolonization of methicillin-resistant Staphylococcus aureus from skin wounds. Viruses, $10(5), 244$.

Dellalibera-Joviliano, R., Melo, S. A., \& Ceni, H. M. R. (2020). Alternativas terapêuticas e aplicação de bacteriófagos como estratégia no uso de antibióticos no tratamento de doenças bacterianas. Revista de Medicina, 99 (1), 88-95.

Elshinawy, M. I., Al-Madboly, L., Ghoneim, W. M., \& El-Deeb, N. M. (2018). Synergistic effect of newly introduced root canal medicaments; ozonated olive oil and chitosan nanoparticles, against persistent endodontic pathogens. Frontiers in Microbiology, 9, e1371.

Giuliani, G., Ricevutti, G., Galoforo, A., \& Franzini, M. (2018). Microbiological aspects of ozone: bactericidal activity and antibiotic/antimicrobial resistance in bacterial strains treated with ozone. Ozone Therapy, 3 (3), 48-51. 
Guinesi, A. S., Andolfatto, C., Bonetti, I., Filho, Cardoso, A. A., Passaretti, J., Filho, \& Farac, R. V. (2011). Ozonized oils: a qualitative and quantitative analysis. Brazilian Dental Journal, 22 (1), 37-40.

Heitkamp, R. A., Li, P., Mende, K., Demons, T. S., Trible, R. D., \& Tyner, D. S. (2018). Association of Enterococcus spp. with severe combat extremity injury, intensive care, and polymicrobial wound infection. Surgical Infections, 19 (1), 95-103.

Kogawa, N. R. A., Arruda, E. J., Micheletti, A. C., Matos, M. F. C., Oliveira, L. C. S., Lima, D. P., Carvalho, N. C. P., Oliveira, P. D., Cunha, M. C., Ojeda, M., \& Beatriz, A. (2015). Synthesis, characterization, thermal behavior, and biological activity of ozonides from vegetable oils. RSC Advances, 5 (80), 6542765436.

Lacey, K. A., Geoghegan, J. A., \& McLoughlin, R. M. (2016). The role of Staphylococcus aureus virulence factors in skin infection and their potential as vaccine antigens. Pathogens, 5 (1), 22.

Li, L., Dai, J., Xu, L., Chen, Z., Li, X., Liu, M., Wen, Y., \& Chen, X. (2018). Antimicrobial resistance and pathogen distribution in hospitalized burn patients: a multicenter study in Southeast China. Medicine, 97 (34), e11977.

Logan, K. L. (2018). Extended-Spectrum Beta-lactamases (ESBL-EC) producing Escherichia coli Urinary Tract Infection treated with Ozone Therapy. Ozone Therapy Global Journal, 8 (1), 145-152.

Lozano-Ledea, O. E., Fernández-García, L. A., Gil-Ibarra, D., Tena, N., Garcés, M. R., Martínez-Force, E., \& Salas, J. J. (2019). Characterization of different ozonized sunflower oils I. Chemical changes during ozonization. Grasas y aceites, 70 (4), 7.

Lu, J., Li, M., Huang, J., Gao, L., Pan, Y., Fu, Z., Dou, J., Huang, J., \& Xiang, Y. (2018). Effect of ozone on Staphylococcus aureus colonization in patients with atopic dermatites. Journal of Central South University. Medical Sciences, 43 (2), 157-162.

Macêdo, M. M. L., Souza, D. A. S., Santos, J. C., Rodrigues, R. N., Afonso, G. S., Cortez, A. O. H., \& Cortez, D. N. (2016). Úlcera venosa: seis años de existencia por 92 días de cicatrización. Gerokomos, 27 (3), 131-133.

Moureu, S., Violleau, F., Haimoud-Lekhal, D. A., \& Calmon, A. (2016). Influence of storage temperature on the composition and the antibacterial activity of ozonized sunflower oil. Ozone: Science \& Engineering, 38 (2), 143-149.

Moureu, S., Violleau, F., Haimoud-Lekhal, D., \& Calmon, A. (2015). Ozonation of sunflower oils: Impact of experimental conditions on the composition and the antibacterial activity of ozonized oils. Chemistry and Physics of Lipids, 186, 79-85.

Néri, J. S. V., Lomba, E., Karam, A. M., Reis, S. R. A., Marchionni, A. M. T., \& Medrado, A. R. A. P. (2017). Ozone therapy influence in the tissue repair process: A literature review. Journal of Oral Diagnosis, 2 (1), 1-6.

Oli, A. N., Eze, D. E., Gugu, T. H., Ezeobi, I., Maduagwu, U. N., \& Ihekwereme, C. P. (2017). Multi-antibiotic resistant extended-spectrum beta-lactamase producing bacteria pose a challenge to the effective treatment of wound and skin infections. The Pan African Medical Journal, 27 (66).

Oliveira, P., Almeida, N., Conda-Sheridan, M., Apparecido, R. P., Micheletti, A. C., Carvalho, N. C., \& Beatriz, A. (2017). Ozonolysis of neem oil: preparation and characterization of potent antibacterial agents against multidrug resistant bacterial strains. RSC Advances, 7 (55), 34356-34365.

Özyıldız, F., Karagönlu, S., Basal, G., Uzel, A., \& Bayraktar, O. (2013). Micro-encapsulation of ozonated red pepper seed oil with antimicrobial activity and application to nonwoven fabric. Letters in Applied Microbiology, 56 (3), 168-179.

Palacios, J. A., \& Rubiano, F. M. (2016). Valoración microbiológica de un aceite ozonizado antibacterial y reparador mediante prueba de eficacia antimicrobiana. Revista Cubana de Farmacia, 50 (4), 1-9.

Pereira, A. S., Shitsuka, D. M., Parreira, F. J., \&Shitsuka, R. (2018). Metodologia da pesquisa científica. [e-book]. Santa Maria. Ed. UAB/NTE/UFSM. Recuperado de: em: https://repositorio.ufsm.br/bitstream/handle/1/15824/Lic_Computacao_Metodologia-Pesquisa-Cientifica.pdf?

Pietrocola, G., Ceci, M., Preda, F., Poggio, C., \& Colombo, M. (2018). Evaluation of the antibacterial activity of a new ozonized olive oil against oral and periodontal pathogens. Journal of Clinical and Experimental Dentistry, 10 (11), e1103.

Silva, D. C., Budó, M. L. D., Schimith, M. D., Ecco, L., Costa, I. K. F., \& Torres, G. V. (2015). Experiências construídas no processo de viver com a úlcera venosa. Cogitare Enfermagem, 20 (1), 13-19.

Silva, V., Marcoleta, A., Silva, V., Flores, D., Aparicio, T., Aburto, I., Latrach, C., \& Febré, N. (2018). Prevalencia y perfil de susceptibilidad antimicrobiana en bacterias aisladas de úlceras crónicas infectadas en adultos. Revista Chilena de Infectología, 35 (2), 155-162.

Smith, N. L., Wilson, A. L., Gandhi, J., Vatsia, S., \& Khan, S. A. (2017). Ozone therapy: an overview of pharmacodynamics, current research, and clinical utility. Medical Gas Research, 7 (3), 212.

Song, M., Zeng, Q., Xiang, Y., Gao, L., Huang, Huang, J., Wu, K., \& Lu, J. (2018). The antibacterial effect of topical ozone on the treatment of MRSA skin infection. Molecular Medicine Reports, 17 (2), 2449-2455.

Souza, M. T., Silva, M. D., \& Carvalho, R. (2010). Integrative review: what is it? How to do it? Einstein (São Paulo), 8 (1), 102-106.

Ugazio, E., Tullio, V., Binello, A., Tagliapietra, S., \& Dosio, F. (2020). Ozonated Oils as Antimicrobial Systems in Topical Applications. Their Characterization, Current Applications, and Advances in Improved Delivery Techniques. Molecules, 25 (2), 334.

Varol, K., Birdane, F. M., \& Keles, I. (2018). Effect of ozonated olive oil on experimentally induced skin infection by Streptococcus pyogenes and Staphylococcus aureus in rats. Indian Journal of Experimental Biology, 56 (9), 657-664.

Whittemore, R., \& Knafl, K. (2005). The integrative review: updated methodology. Journal of Advanced Nursing, 52 (5), 546-553. 
Research, Society and Development, v. 10, n. 2, e22410212451, 2021

(CC BY 4.0) | ISSN 2525-3409 | DOI: http://dx.doi.org/10.33448/rsd-v10i2.12451

Xiang, Y., Lu, J., Li, F., Huang, J., Yang, C., Fu, Z., \& Gao, L. (2018). Bactericidal effect of ozonated camellia oil on Staphylococcus aureus in vitro. Journal of Central South University. Medical Sciences, 43 (2), 139-142.

Zanardi, I. Burgassi, S., Paccagnini, E., Gentile, M., Bocci, V., \& Travagli, V. (2013). What is the best strategy for enhancing the effects of topically applied ozonated oils in cutaneous infections? BioMed Research International, 2013, 1-6.

Zeng, J., \& Lu, J. (2018). Mechanisms of action involved in ozone-therapy in skin diseases. International Immunopharmacology, 56 (138), $235-241$.

Zeng, J., Dou, J., Gao, L., Xiang, Y., Huang, J., Ding, S., Chen, J., Zeng, Q., Luo, Z., Tan, W., \& Lu, J. (2020). Topical ozone therapy restores microbiome diversity in atopic dermatitis. International Immunopharmacology, 80 (138), e106191. 